\title{
HIV surveillance by testing saliva from injecting drug users: a national study in New Zealand
}

\author{
N P Dickson, F J Austin, C Paul, K J Sharples, D C G Skegg
}

\begin{abstract}
Objective - To determine whether the prevalence of HIV infection among injecting drug users in New Zealand has remained low since the introduction of a needle and syringe exchange scheme in May 1988.

Design - Anonymous survey of intravenous drug users attending outlets of the exchange scheme, based on questionnaires and saliva testing.

Setting - Twelve pharmacies and community outreach organisations in six cities.

Subjects - Altogether 620 people provided saliva specimens and completed questionnaires. These represented $73 \%$ of those who visited exchange scheme outlets during a three month period in 1992. Main outcome measure - Saliva was tested for antibodies to HIV-1 and HIV-2 using an IgG-capture enzyme linked immunosorbent assay (GACELISA).

Results - Of 591 specimens eligible for inclusion, only three $(0.5 \%)$ were repeatedly reactive in the GACELISA test, while two of these were also positive in a Western blot test.

Conclusions - Although surveys show that sharing of needles and syringes was common in New Zealand until recently, the prevalence of HIV infection in intravenous drug users has remained low. This can probably be attributed to the success of educational campaigns and legislative action to allow a needle and syringe exchange scheme to be set up.
\end{abstract}

( $\mathcal{F}$ Epidemiol Community Health 1994;48:55-57)

AIDS Epidemiology

Group, Department of Preventive and Social Medicine, University of Otago Medical School, POB 913,

Dunedin, New

Zealand

N P Dickson

C Paul

K J Sharples

D C G Skegg

Virus Research Unit, Department of Microbiology,

University of Otage

Medical School,

Dunedin, New

Zealand

F J Austin

Correspondence to:

Professor D Skegg.

Accepted for publication

November 1993
By 1991, injecting drug users who were not homosexual or bisexual men accounted for $24 \%$ of new cases of AIDS in the United States, ${ }^{1}$ and $38 \%$ in the WHO European region. ${ }^{2}$ Intravenous drug users are now the though the pattern varies strikingly between countries. Thus, intravenous drug users constituted $66 \%$ of all cases of AIDS reported by 30 June 1992 in Italy, 37\% in Switzerland, but only $4.5 \%$ in the United Kingdom. ${ }^{2}$ In New Zealand the proportion on the same date was even lower at $2 \cdot 1 \%$ (seven of 335 cases). ${ }^{3}$

The evolution of the AIDS epidemic in New Zealand has been similar to that in the United Kingdom. The cumulative incidences to 30 June 1992 were $10 \cdot 2$ per 100000 in New Zealand and 10.8 per 100000 in the United Kingdom. The rarity of AIDS affecting intraleading transmission group in Europe, al- venous drug users in New Zealand cannot be attributed to absence of drug injecting. In a telephone survey of 5126 people aged 15-45 years selected at random from two regions of New Zealand in 1990, 0.9\% admitted having used needles to inject drugs in the past. ${ }^{4}$ Sharing of needles and syringes has also been common, ${ }^{56}$ but a needle and syringe exchange scheme was instituted in May $1988 .^{7}$ There is usually a long delay between HIV infection and the development of AIDS, and many countries have experienced a very rapid spread of HIV among intravenous drug users. ${ }^{8}$ We therefore conducted a national survey to determine whether the prevalence of HIV infection has remained low in intravenous drug users in New Zealand.

\section{Methods}

Information was obtained from the one company supplying equipment for the needle and syringe exchange scheme about the distribution of 205600 needles and syringes (in packs of 10) during the 11 months to 28 February 1992. Pharmacies and community outreach organisations in six centres (Auckland, Palmerston North, Wellington, Nelson, Christchurch, and Dunedin) received $79 \%$ of all needles and syringes distributed for this purpose in New Zealand. The busiest outlets in each city were identified, and 16 were invited to participate. These outlets had received $71 \%$ of the needles and syringes distributed to the six centres.

During a three month period from April 1992 , the outlets were asked to give all clients of the exchange scheme information about the study (including an information sheet). Clients were requested to complete a brief, anonymous questionnaire and to provide a saliva specimen by chewing on a small roll of cotton wool. No names or other identifying particulars were collected, so that results could not be linked to individuals. Participants were advised where they could obtain a test if they wished to know their HIV status. They were asked not to take part again if they had already provided a sample during the survey period. A small carton of fruit juice was given to each participant as a token of thanks.

After chewing on the cotton wool until it became soggy, participants put it into a specially designed plastic tube (Salivette, Sarstedt). The tube and completed questionnaire were then placed in a plastic bag, which was refrigerated before being taken to the laboratory in a weekly batch. Saliva was extracted from the cotton wool by centrifugation and frozen at $-20^{\circ} \mathrm{C}$. It was tested for antibodies 
to HIV-1 and HIV-2 using an IgG-capture enzyme linked immunosorbent assay (GACELISA, Wellcome Diagnostics). Samples found to be reactive in this test were retested twice. If either of the repeat tests was reactive, the sample was sent for confirmatory testing using the Western blot technique. Such samples were diluted $(1: 100)$ before being tested.

Before beginning the study reported here, a pilot study was conducted in a Dunedin pharmacy and community outreach organisation. Saliva samples were also tested from 10 people known to be HIV positive and from nine people known to be HIV negative; the test correctly identified the status of all 19 subjects.

\section{Results}

Of the 16 outlets invited to participate, two declined and two failed to forward specimens. The remaining 12 outlets returned 620 saliva specimens and questionnaires. Demographic information was also obtained about the 228 users of these outlets who declined to participate. Thus, the response rate was $73 \%$ (620 of 848 ). The intravenous drug users who refused to participate were similar to participants with regard to sex and age, but included a higher proportion of Maori people (17\% compared with $9 \%$ of participants).

The 620 people who participated included 17 who indicated on their questionnaires that they had already provided a saliva specimen during the period of the study, and two who stated that they had never injected drugs. Of the remaining 601 subjects, 10 provided insufficient saliva for testing. The sex and age groups of the 591 people tested are shown in the table. There were 507 people of European origin, 52 Maoris, five Pacific Islanders, 20 others, and seven who did not state their ethnic group. The intravenous drug users had obtained their needles and syringes from community outreach organisations in 368 cases $(62 \%)$ and pharmacies in $223(38 \%)$.

On testing for HIV antibodies, three $(0.5 \%)$ of the 591 specimens were repeatedly reactive in the GACELISA test, and two of these were also positive in the Western blot test. All three subjects were European men using community outreach organisations - two in Wellington and one in Auckland. Their age groups were 25-29 years (2) and 35-39 years (1). These men were all among the $43 \%$ of subjects who stated that they injected drugs weekly or less often.

Characteristics of the 591 intravenous drug users tested

\begin{tabular}{lcclc}
\hline Age group $(y)$ & Male & Female & Sex not stated & Total \\
\hline $15-19$ & 11 & 10 & - & 21 \\
$20-24$ & 73 & 59 & 2 & 134 \\
$25-29$ & 144 & 61 & - & 205 \\
$30-34$ & 98 & 34 & 1 & 133 \\
$35-39$ & 47 & 18 & - & 65 \\
$40-44$ & 15 & 5 & - & 20 \\
$45-49$ & 2 & 1 & - & 3 \\
Not stated & 3 & 2 & 5 & 10 \\
Total & 393 & 190 & 8 & 591 \\
\hline
\end{tabular}

\section{Discussion}

Since the first cases of AIDS were diagnosed in New Zealand in 1983, the epidemic has largely involved men who have had sex with other men. ${ }^{9}$ Among 360 cases notified by 31 December 1992, $314(87 \%)$ were in this category (seven of these had also injected drugs). ${ }^{10}$ Only eight other intravenous drug users have developed AIDS (five men and three women). All of these eight people had injected drugs overseas. Such figures could give false reassurance, however, since HIV can spread very rapidly in populations injecting drugs and there is usually a long delay before the development of AIDS.

New Zealand has a substantial population of intravenous drug users. From a survey conducted in $1990,{ }^{4}$ it was estimated that about $1 \%$ of New Zealanders aged 15-45 (or 16000 people) have ever injected drugs. ${ }^{11}$ The number of current intravenous drug users is believed to be between 3000 and 7000 people. ${ }^{11}$ In 1992, there were 18 methadone programmes catering for 892 clients, with several programmes reporting waiting lists. While most intravenous drug users state that heroin would be their drug of choice, its availability is limited and many use morphine, other pharmaceuticals, "homebake" (derived from codeine), or opium poppies. ${ }^{6}$ Surveys in 1985 , 1986 , and 1987-88 showed that sharing of needles and syringes was common. ${ }^{56}$ This is reflected in a high prevalence of hepatitis $C$ virus infection in intravenous drug users, with a recent survey finding that $73 \%$ attending a treatment centre were infected. ${ }^{12}$

The best approach for the surveillance of HIV infection in sentinel populations is the unlinked anonymous monitoring of left-over blood specimens collected for other purposes, because this avoids participation bias. ${ }^{13}$ Unfortunately, this is not feasible for studying intravenous drug users because, unlike other groups such as patients attending sexually transmitted disease clinics, ${ }^{14}$ they do not routinely have blood taken. Moreover, patients attending treatment clinics such as methadone programmes are not generally typical users. In a recent American survey, IIV infection was found to be twice as common in communityrecruited intravenous drug users as in those entering treatment programmes during the same period. ${ }^{15}$ Since surveillance of intravenous drug users requires voluntary participation, the method of sample collection should not discourage this. Intravenous drug users in Ontario were found to be more likely to agree to provide a saliva specimen than a fingerprick specimen of blood. ${ }^{16}$ Another advantage of using saliva is that it can be collected safely in difficult field conditions by people with minimal training. The development of IgG capture assays for HIV antibodies (such as the GACELISA method used in this study) has made highly sensitive saliva tests available for epidemiological research. ${ }^{1718}$

Saliva testing has been used to evaluate needle exchange schemes in central London ${ }^{19}$ and Toronto, ${ }^{16}$ and to monitor the prevalence of HIV infection among intravenous drug 
users in England and Wales. ${ }^{20}$ We used this approach in a national survey of intravenous drug users obtaining needles and syringes from community outreach organisations and pharmacies. The study has three limitations: that only a proportion of outlets were included, that a quarter of those using the outlets during the survey period declined to participate, and that those not using the exchange scheme were not included. Since even intravenous drug users with ready access to needles and syringes are liable to share equipment from time to time, ${ }^{7}$ however, it is likely that any appreciable rise in HIV prevalence among subpopulations would be accompanied by evidence of infection among the people we tested. The conclusion from this study that HIV infection is still very uncommon among intravenous drug users in New Zealand is supported by two other observations. Firstly, when washings were taken from 759 randomly selected syringes returned in the exchange scheme in 1990, only two were unequivocally positive for HIV antibody (although it is possible that cleaning of syringes by intravenous drug users, particularly with bleach, could have led to some false negative results). ${ }^{21}$ Secondly, in unlinked anonymous monitoring of HIV prevalence at sexually transmitted disease clinics between August 1991 and August 1992, only two of 208 heterosexual men and none of 151 women known to have injected drugs were found to be infected. ${ }^{14}$

Why has the prevalence of HIV infection remained low among intravenous drug users in New Zealand? Spread of HIV among intravenous drug users requires a mechanism for efficient mixing of susceptibles with people infected with HIV. The current rarity of HIV infection among intravenous drug users in New Zealand could possibly stem from relative geographic isolation and good fortune. Nevertheless, New Zealanders travel extensively and a number have developed AIDS after injecting drugs overseas. The high prevalence of hepatitis $C$ virus infection among injecting drug users group suggests that needle sharing behaviour has existed in a form which allowed transmission of blood borne viruses. Thus, it is likely that the low prevalence of HIV is due to changes in behaviour.

The HIV/AIDS epidemic in New Zealand is believed to have started later than in the USA or Britain, so there was the opportunity to introduce prel ention programmes while the prevalence of HYV in intravenous drug users was still very low. AIDS education campaigns in New Zealand have included information about the dangers of needle sharing. In 1986 a special pamphlet was widely distributed to intravenous drug users, and this included advice on how to clean equipment. After extensive public debate, the Misuse of Drugs Amendment Act (1987) was passed to enable the establishment of a needle and syringe exchange scheme (under special regulations) in May 1988. This scheme has increased dramatically the availability of clean equipment, and an evaluation conducted after the first year showed a reduction in sharing. ${ }^{7}$ Further research could assess whether this reduction has persisted, and whether hepatitis $C$ virus infection becomes common among young people who have started injecting drugs since the exchange scheme began. It is fashionable to imply that attempts to control AIDS by influencing human behaviour are doomed to fail, as if only the availability of a vaccine could modify an inexorable progress. While there is always the potential for rapid spread of HIV among intravenous drug users in New Zealand, their fortunate experience so far can probably be attributed to educational activities, changes in public policy, and legislative action.

This study was supported by the Health Research Council of New Zealand. We thank the pharmacists and workers in community outreach organisations who collected and forwarded specimens and questionnaires, Dr M C Croxson and Marjorie Bridle for conducting the Western blot tests, and D G M Robinson for advice. Salmond Smith Biolab assisted us by providing information about the distribution of needles and syringes in the exchange scheme.

1 Centers for Disease Control. Update: acquired immunodeficiency syndrome - United States, 1991. MMWR 1992;41:463-8.

2 European Centre for the Epidemiological Monitoring of AIDS. AIDS surveillance in Europe. Quarterly Report No 34. Saint-Maurice: Hôpital National de Saint-Maurice, 30 June 1992.

3 AIDS Epidemiology Group. AIDS-New Zealand. Issue 14 Dunedin: Department of Preventive and Social Medicine University of Otago Medical School, August 1992.

4 Black S, Casswell S. Drugs in New Zealand - a survey, 1990 Auckland: Alcohol and Public Health Research Unit, University of Auckland, 1991.

5 Robinson GM, Thornton NJ, Rout J, Mackenzie N. AIDS risk behaviours and AIDS knowledge in intravenous drug users. NZ Med f 1987;100:209-11.

6 Lungley S. Intravenous drug use in New Zealand. Wellington: Health Services Research and Development Unit, ington: Health Services Research and Development

7 Lungley S, Baker M. The needle and syringe exchange scheme in operation. Wellington: Health Research Services, Dein operation. Wellington: Health Research Service

8 Des Jarlais DC, Friedman SR, Choopanya K, Vanichseni S Ward TP. International epidemiology of HIV and AIDS among injecting drug users. AIDS 1992;6:1053-68.

9 Carlson RV, Skegg DCG, Paul C, Spears GFS. Occurrence of AIDS in New Zealand: the first seven years. NZ Med $\mathfrak{f}$ 1991;104:131-4

10 AIDS Epidemiology Group. AIDS-New Zealand. Issue 16 Dunedin: Department of Preventive and Social Medicine, University of Otago Medical School, February 1993.

11 Department of Health. Drug statistics 1992. Wellington: Department of Health, 1992

12 Woodfield DG, Harness M, Rix-Trott K. Hepatitis C virus infections in oral and injectable drug users. NZ Med of 1993;106:3324.

13 WHO Global Programme on AIDS. Unlinked anonymous screening for the public health surveillance of HIV infections: proposed international guidelines. Geneva: World Health Organization, 1989; WHO publication no GPA Health Or

14 Dickson NP, Paul C, Skegg DCG et al. Unlinked anonymous monitoring of HIV prevalence at sexually transmitted disease clinics. NZ Med f 1993;106:325-7.

15 Lampinen TM, Joo E, Seweryn S, Hershow RC, Wiebel W. HIV seropositivity in community-recruited and drug treatment samples of injecting drug users. AIDS 1992;6:123-6

16 Major CJ, Read SE, Coates RA, et al. Comparison of saliva and blood for human immunodeficiency virus prevalence testing. F Infect Dis 1991;163:699-702.

17 Parry JV, Perry KR, Mortimer PP. Sensitive assays for viral Po tosts on serum. Lancet 1987;ii:72-5.

18 Crofts N, Nicholson S, Coghlan P, Gust ID. Testing of saliva for antibodies to HIV-1. AIDS 1991;5:561-3.

19 Hart GJ, Carvell ALM, Woodward N, Johnson AM, Williams $P$, Parry JV. Evaluation of noedle exMan, W liams $P$, Parry JV. Evaluation of needle exchange in central London: behaviour change
over one year. $A I D S$ 1989;3:261-5.

20 Public Health Laboratory Service. Unlinked anonymous monitoring of HIV prevalence in England and Wales: monitoring of HIV prevalence in England and Wales: no 1):R1-11.

21 Baker M, Brady H, Tobias M. Detection of HIV antibodies in used syringes in New Zealand. Communicable Disease New Zealand; 1992;92:13-18. 